\title{
FOREWORD
}

\section{SYMPOSIUM: ECOSYSTEM DISRUPTIONS IN THE AMERICAS}

\author{
Disrupciones ecosistémicas en las Américas
}

\author{
PABLO A. MARQUET ${ }^{1} \&$ G.A. BRADSHAW ${ }^{2}$ \\ ${ }^{1}$ Center for Advanced Studies in Ecology and Biodiversity \& Departamento de Ecología, \\ Pontificia Universidad Católica de Chile, Casilla 114-D, Santiago, Chile; \\ e-mail: pmarquet@bio.puc.cl \\ ${ }^{2}$ Environmental Sciences Programme and Department of Forest Science, Oregon State University, Corvallis, \\ Oregon 97331, USA; e-mail: gay.bradshaw @ orst.edu
}

Understanding the effects of human-induced perturbations, "disruptions", on ecosystem functions is essential to be able to design sustainable environmental practices for the protection of biodiversity. It has been welldocumented on all continents that EuroAmerican cultures have had severe and deleterious effects upon biodiversity during the last three centuries (Deloria 1996). Human impacts since New World colonisation have accelerated species extinctions and the disruption and degradation of ecosystems processes and services, many of which have already been reduced to isolated fragments, and numerous species and genetically distinct populations have been lost in the process. In fact, between one-third to one half of the land surface have been transformed by human action (Vitousek et al. 1997) and is currently composed of what Brown et al. (2003) call "semi-natural matrix" or "...land neither intensively used for cities or agriculture nor set aside as natural reserves." Perhaps more disturbing are the less well-known and more subtle disruptions to fundamental ecosystem processes: the consequences of which are yet to be seen.

During this new millennium, the tragedy of the commons is likely to become more common, particularly in developing countries where the pressures are both global and local. Under these circumstances, environmental scientists face the challenge of providing the information upon which future social and environmental policy needs to be based. This challenge requires a careful scrutiny and examination of scientific data, models and other available empirical evidence within an interdisciplinary setting. Other critical tasks include: (1) the explicit consideration of the interaction between science and society in developing sustainable initiatives (Bradshaw \& Bekoff 2001), (2) systematic collection of data in the form of large scale monitoring of ecosystem patterns and processes and, (3) the synthesis of available knowledge. All objectives are necessary to adequately address the problem of environmental decline. However, the task is not easy.

Nearly three decades ago, various scientists from the Americas began to think about how to address these types of problems. What emerged was an international effort to investigate global change effects by profiting from the use of natural experiments; namely the comparison of North and South Americas.

North and South American ecosystems share a long history of cultural and ecological interactions and have sustained similar transformations and disruptions through human impacts. Both continents are subject to largescale climatic drivers such as the ENSO phenomenon. To a certain extent, North and South America exist as mirror images of each other in climatic and biological patterns. This is particularly true for the western regions of North and South America where similar progressions of major ecosystems types exist, along and in similar geographic and geological settings, respectively. Temperate areas in North and South America share striking climatic similarities, notwithstanding their biogeographic, cultural and socioeconomic differences. For example, the analysis of global circulation models (Lauenroth et al. 2004) predict that under a scenario of an effecting doubling of $\mathrm{CO}_{2}$, in temperate areas of both continents deserts will expand at the expense of grasslands, which in turn will expand at the expense of boreal forest in North America. Even though it is anticipated that the effects of climatic changes will be substantially different between hemispheres (i.e., southern hemisphere landmasses are smaller, polar ice masses closer, and land-to-ocean ratios smaller), the two continents provide a unique multi-scale laboratory for diverse scientists. In addition to 
a shared biology, both hemispheres have an increasingly similar economic environment and are becoming more interdependent in terms on natural products, capitals and political agendas. Under this scenario, inter-hemispheric, comparative analyses (e.g., Mooney et al. 1993) are not only useful but necessary to accurately model and predict continental, regional and local impacts upon ecosystems.

The predicted similarities and differences in the anticipated responses to climate change constitute an implicit set of scientific hypotheses on the climatic control of vegetation and attendant effects on flora and fauna. By utilizing the comparative approach, scientists are able to develop a solid foundation for predicting future scenarios of climate change. In 1990, several scientists from North and South America established a research organization called AMIGO (America's Interhemisphere Geo-biosphere Organization) aimed at understanding ecosystem responses to global change by comparing the patterns and processes in the responses of analogous ecosystems in North and South America. AMIGO has help to organize several workshops the last two of which are the core of the present special issue.

The alteration of ecosystem and disruption of disturbance cycles via diverse human actions such -exotic species introduction, rapid land conversion, habitat degradation, and fragmentation- form a common thread among scientists and resource managers in both southern and northern hemispheres. To further our understanding on these issues, in June 1995 a workshop was held at Stanford University, California, USA, to examine natural and human induced disruptions of ecosystem functions and linkages by comparing Western temperate ecosystems in North and South America. A second workshop in December 1997, was held in Maitencillo, Chile, to examine the drivers, consequences, and management of landscape alteration in the Americas. The participants, in both workshops, were selected to represent a spectrum of disciplines reflecting the requisite perspectives and integration for problem analysis. The results presented at both conferences were published in the book, "How Landscapes Change" (Bradshaw \& Marquet 2003) and in this special section.

As the reader will see, the five papers comprising this section provide updated overviews of ecosystem disruptions in marine environments (Halpin et al. 2004) and focus on agents of disruption whose impact seems strong in the Americas such as fire (Montenegro et al. 2004) and exotic species (Dukes \& Mooney 2004, Figueroa et al. 2004). Finally, Lauenroth et al. (2004) address the large scale consequences of climate change. We hope that through this special section, natural scientists will get an overview of the dimension and impact of humans upon ecosystems in the Americas and stimulate further comparative research and collaboration

\section{LITERATURE CITED}

BRADSHAW GA \& M BEKOFF (2001) Ecology and social responsibility: a re-embodiement of science. Trends in Ecology and Evolution 16: 460-465.

BRADSHAW GA \& PA MARQUET (eds) (2003) How landscapes change. Human disturbance and ecosystem fragmentation in the Americas. SpringerVerlag, Berlin, Germany. Xxi + 361pp.

BROWN JH, CG CURTIN \& RW BRITHWAITE (2003) Management of the semi-natural matrix. In: Bradshaw GA \& PA Marquet (eds) How landscapes change. Human disturbance and ecosystem fragmentation in the Americas: 327-343. SpringerVerlag, Berlin, Germany.

DELORIA V, Jr (1996) God is red. Fulcrum Publishing, Denver, Colorado, USA. 320 pp.

DUKES JS \& HA MOONEY (2004) Disruption of ecosystem processes in western North America by invasive species. Revista Chilena de Historia Natural 77: 411-437.

FIGUEROA JA, SA CASTRO, PA MARQUET \& FM JAKSIC (2004) Exotic plant invasions to the Mediterranean region of Chile: causes, history and impacts. Revista Chilena de Historia Natural 77: 465-483.

HALPIN PM, PT STRUB, WT PETERSON \& TM BAUMGARTNER (2004) An overview of interactions among oceanography, marine ecosystems, climatic and human disruptions along the eastern margins of the Pacific Ocean. Revista Chilena de Historia Natural 77: 371-409.

LAUENROTH WK, HE EPSTEIN, JM PARUELO, IC BURKE, MR AGUIAR \& OE SALA (2004) Potential effects of climate change on the temperate zones of North and South America. Revista Chilena de Historia Natural 77: 439-453.

MOONEY HA, ER FUENTES \& BI KRONBERG (eds) (1993) Earth sytem responses to global Change. Constrats between North and South America. Academic Press, San Diego, California, USA. xxii+365 pp.

MONTENEGRO G, R GINOCCHIO, A SEGURA, JE KEELY \& M GÓMEZ (2004) Fire regimes and vegetation responses in two Mediterranean-climate regions. Revista Chilena de Historia Natural 77: 455464.

VITOUSEK PM, HA MOONEY, J LUBCHENCO \& JM MELILLO (1997) Human domination of earth's ecosystems. Science 277: 494-499. 